Int. J. Biometeor. 1977, Vol. 21, number 2, pp. 135-146.

\title{
Developmental Adaptation to High Altitude Hypoxia
}

\author{
by
}

\author{
A. R. Frisancho
}

\begin{abstract}
Experimental studies on animals and humans exposed to hypoxic stress have been reviewed. These data suggest that the influence of hypoxic stress, and the organism's response to it, are greater during growth than during adulthood. The organism's responses include alterations in the quantity and size of the alveolar units of the lungs, enlargement of the right ventricle of the heart, slower somatic growth as measured by birth weight and body size, increased aerobic capacity during maximal work, and greater control of ventilation. It is postulated that the organism is more sensitive to the influence of environmental factors during growth and development than during adulthood. Consequently, adaptive traits acquired during the developmental period have profound, long-term consequences, which are reflected in the physiological and morphological characteristics of the adult organism. It is concluded that the differences between the highland and lowland natives in their physiological performance and morphology are mostly due to adaptations acquired during the developmental period.

Attention is called to the fact that the principle of developmental sensitivity and plasticity does not imply equally adaptive responses in all biological parameters. In other words, what we consider a deficiency in a given variable may actually reflect the indirect influence of the adaptive success of another variable.
\end{abstract}

\section{INTRODUCTION}

During growth and development, environmental factors are constantly conditioning and modifying the expression of inherited potential. The influence of the environment on the organism depends on the type of stress imposed and especially on the age at which the individual is subjected to the stress. Hence, the contributions of genetic and environmental factors vary with the developmental stage of the organism and, in general, the earlier the age, the greater the influence of the environment. Thus, in previous publications we have postulated that the differences between the highland and the lowland native in terms of physiological performance and morphology are due in part to adaptations acquired during the developmental period (Frisancho, 1975; Frisancho, Velasquez and Sanchez, 1973; Frisancho et al., 1973). It is the purpose of the present article to summarize the evidence that supports this hypothesis.

\footnotetext{
* Center for Human Growth and Development, University of Michigan 1111 East Catherine Street, Ann Arbor, Michigan 48109, USA.

Presented at the Seventh International Biometeorological Congress, 17-23 August 1975, College Park Maryland, USA.
} 


\section{LUNG VOLUME AND PULMONARY DIFFUSING CAPACITY}

Several investigations have documented that vital capacity and residual lung volume of sea level natives sojourning at high altitudes will remain unchanged, after an initial reduction, when compared to values attained at sea level (Consolazio et al., 1967; Rahn and Hammond, 1952). In contrast, after adjustments are made for differences in body size, highland natives have a larger lung volume, especially a larger residual lung volume, than subjects from low altitudes (Frisancho, Velasquez and Sanchez, 1973; Hurtado, 1932). As inferred from studies of children, the enlarged lung volume of the high altitude native is attained through a rapid and accelerated development during childhood and adolescence (Frisancho, 1969; Hurtado, 1932). Since at low altitudes growth in lung volume during childhood is associated with the proliferation of alveolar units and alveolar surface area (Dunnill, 1962), the rapid growth seen among highland children is probably also associated with an increase in alveolar units and alveolar surface area. Studies invariably indicate that the pulmonary diffusing capacity of the highland native is systematically greater than that attained by lowland natives at low altitudes (DeGraff et al., 1970; Guleria et al., 1971; Remmers and Mithoefer, 1969; Velasquez and Florentini, 1966). Since the pulmonary diffusing capacity is related in part to the alveolar surface area, the enhanced pulmonary diffusing capacity of the highland native is probably due to a greater alveolar area and an increased capillary volume.

With a view toward determining the role of developmental factors in the attainment of enlarged lung volume, we recently studied the forced vital capacity of lowland subjects and highland natives. As shown in Table 1 , the lowland natives who were accli-

TABLE 1. Covariance adjustment of forced vital capacity (adjusted for age, weight, and height) among subjects tested at high altitudes. After Frisancho, Velasquez and Sanchez (1973).

\begin{tabular}{clcc}
\hline $\mathrm{n}$ & Group & \multicolumn{2}{c}{ Forced vitalcapacity (ml) } \\
\cline { 3 - 4 } & & Mean & $\mathrm{SE}$ \\
\hline \multirow{2}{*}{40} & Subjects tested at 3,840 $\mathrm{m}$ & 4830.3 & 69.9 \\
13 & High altitude natives & & \\
& Sea level subjects acclimat- & & \\
F ratio & ized as adults & 4504.6 & 122.1 \\
& & 5.19 & $\mathrm{P}<0.02$ \\
20 & Subjects tested at 3,400 $\mathrm{m}$ & & \\
21 & High altitude natives & 4990.3 & 128.6 \\
F ratio & Sea level subjects acclimatized during growth & 5055.0 & 121.5 \\
10 & White North American subjects acclimatized & 0.36 & $\mathrm{NS}$ \\
& as adults* & 4573.9 & 231.6 \\
F ratio & & 5.53 & $\mathrm{P}<0.02$ \\
\hline
\end{tabular}

* When compared with the high altitude natives tested at $3,840 \mathrm{~m}$ and $3,400 \mathrm{~m}$.

matized to high altitude during growth attained, after adjustments for variations in body size, the same values of forced vital capacity as the highland natives. In contrast, lowland natives (Peruvian and North American subjects) acclimatized as adults had significantly lower vital capacities than highland natives. We thus postulated that the enlarged vital capacity of the highland native is the result of adaptations occurring during growth and development (Frisancho, Velasquez and Sanchez, 1973). 
This hypothesis is supported by experiments conducted on animals. Various studies (Bartlett, 1972; Bartlett and Remmers, 1971; Burri and Weibel, 1971) have demonstrated that after prolonged exposure to high altitude hypoxia $(3,450 \mathrm{~m})$ young rats exhibit an accelerated proliferation of alveolar surface area and lung volume. In contrast, adult rats after similar exposure to high altitude hypoxia did not show changes in alveolar quantity and lung volume (Burri and Weibel, 1971; Cunningham, Brody and Jain, 1974). These findings suggest that in experimental animals and in man the enlarged lung volume at high altitude is probably mediated by developmental factors.

\section{PULMONARY CIRCULATION}

Histological studies have demonstrated that after the first month of postnatal development, children born at high altitudes show a thickening of the muscular layer and a muscularization of the pulmonary arterioles that resemble the development of the fetal vascular tree (Arias-Stella and Saldana, 1962). These characteristics contribute to the increased pulmonary vascular resistance or pulmonary hypertension in the high altitude resident and native (Banchero et al., 1966; Penaloza et al., 1963; Sime et al., 1963). Based on studies of steers, the hypothesis has been that pulmonary hypertension at high altitudes would favor a more effective profusion of all the pulmonary areas, and therefore, increase the effective blood-gas interfacial area of the alveoli (Grover et al., 1963). In this manner, perfusion of the entire lung coupled with an increased vascularization would enhance the diffusing capacity of the lung and should also decrease the difference between the arterial and the alveolar blood. These changes would permit a more effective oxygenation of the arterial blood. However, one cannot assume that pulmonary hypertension would necessarily decrease the arterial-alveolar gradient in man, and the application of this hypothesis to the adaptation of human beings to high altitudes remains to be tested.

As a result of the increased pulmonary resistance or hypertension, the right ventricle of the heart of the high altitude resident and native is enlarged, as shown by anatomical and electrocardiographic studies (Arias-Stella and Recavarren, 1962; Harris and Hansen, 1966; Penaloza et al., 1964; Rotta et al., 1956). The enlargement of the right ventricle may also be related to the high prevalence of patent ductus arteriosus among highland children (Marticorena et al., 1962). Hence, because of the pressure differential between the aorta and the pulmonary artery, the work of the right ventricle of the heart may be increased. The high incidence of patent ductus arteriosus may be a consequence of fetal and newborn hypoxia and may also be one of the sources of the pulmonary hypertension. Lowland natives with pattern ductus arteriosus also commonly suffer from right ventricular hypertrophy and pulmonary stenosis.

Although pulmonary hypertension and right ventricular hypertrophy may occur at all ages in both highland and lowland subjects in their native environments, these characteristics are accentuated among subjects exposed to insufficient oxygen supplies during childhood and adolescence (Arias-Stella and Recavarren, 1962; Banchero et al., 1966; Penaloza et al., 1963; Sime et al., 1963). These findings demonstrate the influence of developmental factors in the acquisition of the cardiovascular characteristics of the highland native.

\section{PRENATAL AND POSTNATAL GROWTH IN BODY SIZE}

Petropoulos and Timiras (1974) have summarized the available evidence related to hypoxic effects on prenatal and postnatal growth. These studies indicate that prenatal growth, as judged from evaluations of birth weight, is retarded among experimental animals raised at high altitude when compared to sea level controls with equal dietary intakes (Delaquerriere-Richardson, Forbes and Valdivia, 1965; Johnson, Taylor and 
DeGraff, 1965; Nelson and Srebnik, 1970). These findings are in agreement with those published for humans. Studies in the U.S. and Peru indicate that birth weight among high altitude populations is lower than in comparable sea level populations (Lichty et al., 1957; Baker, 1969; Frisancho, 1970; Grahn and Kratheman, 1963; Hoff, 1974; Kruger and Arias-Stella, 1970; McClung, 1967; Pawson, 1974; Sobrevilla et al., 1967; U.S. Publ. HIth., 1965; Weinstein and Haas, 1975).

The decrease in birth weight among high altitude populations is not associated, however, with a decrease in placental weight. On the contrary, studies in animals (Nelson and Srebnik, 1970; Petropoulos, 1971) and on humans (Frisancho, 1970; McClung, 1969; Sanchez, 1963; Sobrevilla and Salazar, 1968) indicate that the placental weight at high altitude is either equal to or greater than that at sea level. In either case, the placental weight/newborn weight ratio at high altitude is higher than at sea level. It has been postulated that the relatively greater weight of the placenta reflects a prenatal adaptive mechanism to the low oxygen availability of high altitudes (Frisancho, 1970; McClung, 1969; Sobrevilla, 1971). However, as indicated by Petropoulos and Timiras (1974) this hypothesis remains to be experimentally substantiated.

The pattern of slow prenatal development inferred from studies of birth weight continues during postnatal development. In high altitude rats this retarded growth results in a $30 \%$ reduction in adult body weight, even in cases where birth weights were equivalent to sea level rats (Weihe, 1965; Kelley and Pace, 1968; Petropoulos and Timiras, 1974). Studies in humans indicate that growth in body size during infancy, childhood and adolescence is delayed at high altitude when compared to growth in sea level counterparts (Frisancho, 1969; Baker, 1969; Frisancho and Baker, 1970; Haas, 1973; Boyce et al., 1974). Using intra-and inter-populational comparisons of genetic similarities and parent-offspring correlation coefficients, it has been concluded that the retarded growth of high altitude children is related to the synergic influence of hypoxic stress and nutritional factors associated with high altitude environments (Frisancho, 1976).

\section{WORK CAPACITY}

LOWLAND NEWCOMERS TO HIGH ALTITUDES. - It is generally agreed that the maximum oxygen intake per amount of body weight during maximal activity (aerobic capacity) is a measure of the individual's work capacity because it reflects the capacity of the working muscles to utilize oxygen and the ability of the cardiovascular system to transport and deliver oxygen to the tissues. Studies of newcomers to high altitudes demonstrate a reduction in aerobic capacity of from 13 to $22 \%$ (Adams et al., 1975; Balke, 1960; Buskirk et al., 1967; Consolazio et al., 1967; Dill et al., 1967; Faulkner et al., 1968; Grover et al., 1967; Kollias et al., 1968). The maximum aerobic capacity of fit lowland natives at high altitudes, when expressed as a percentage of the values attained at sea level, declines by $3.2 \%$ for every $300 \mathrm{~m}$ ascended beyond $1,500 \mathrm{~m}$ (Buskirk et al., 1967). In contrast, the aerobic capacity of highland natives such as Andean Quechuas and Himalayan Sherpas is comparable to that attained by lowland natives at sea level (Baker, 1969; Buskirk et al., 1967; Elsner, Bolstad and Forno, 1964; Grover et al., 1967; Kollias et al., 1968; Lahiri, 1966; Mazess, 1969; Velasquez, 1964).

DEVELOPMENTAL RESPONSE. - To determine the influence of developmental factors on functional adaptation to high altitude, my co-workers and I recently conducted an investigation of aerobic capacity (Frisancho, Velasquez and Sanchez, 1973; Frisancho et al., 1973). As shown in Table 2, the lowland natives, when acclimatized to high altitude during childhood and adolescence, attained an aerobic capacity and pulmonary ventilation equal to that of the highland natives. Furthermore, in both groups the volume of air ventilated per unit of oxygen consumed, the increase in heart rate and the volume of oxygen consumption per pulse rate, are highly comparable. In contrast, lowland natives (Peruvian and North American subjects) when acclimatized 
to high altitudes as adults attained significantly lower aerobic capacities and higher pulmonary ventilation than the highland natives. Similarly, these lowland subjects attained a significantly higher ventilation ratio and lower heart rate than the highland natives.
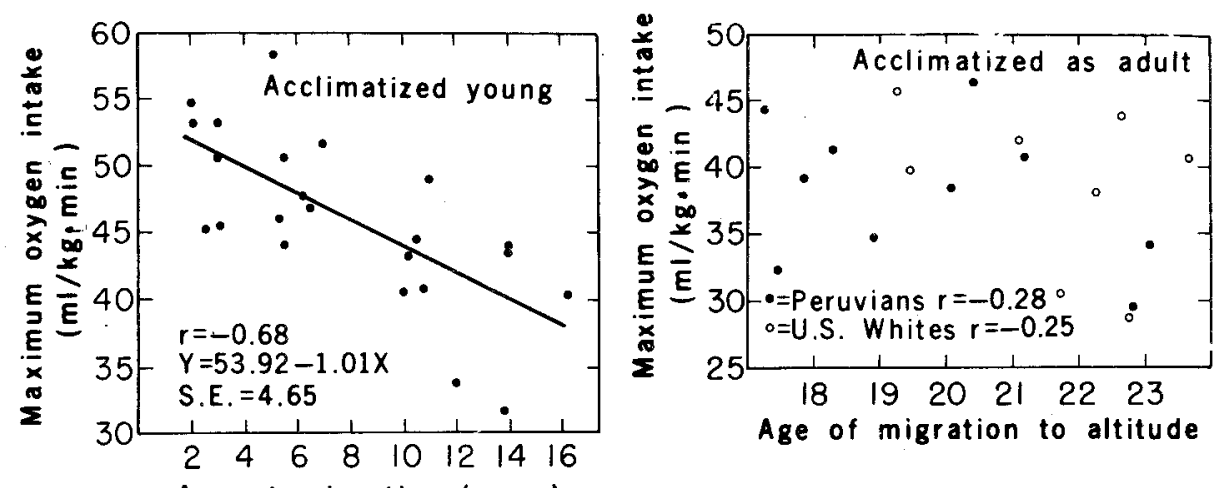

Age at migration (years)
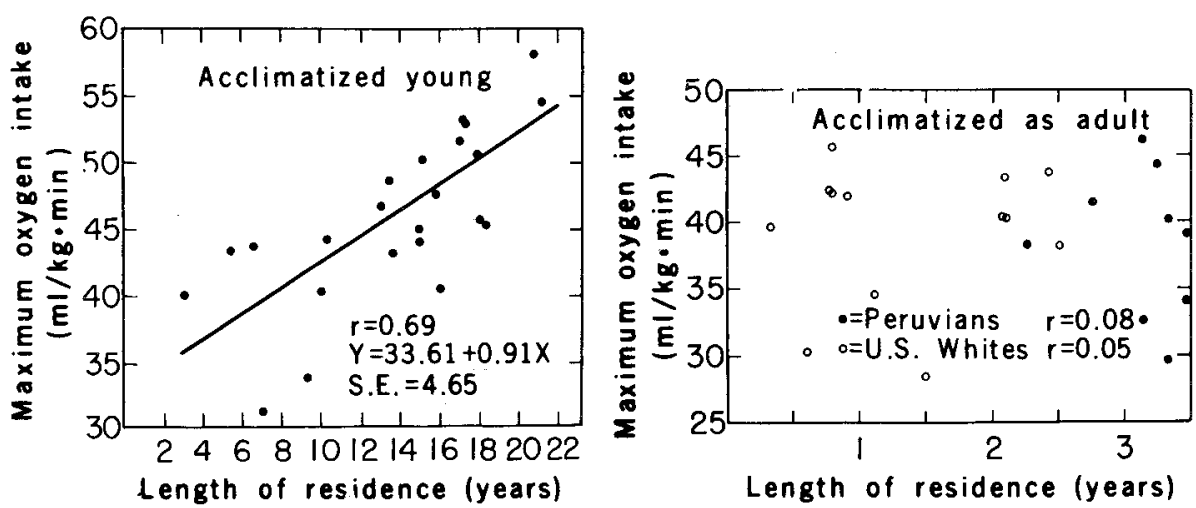

Fig. 1. Influence of developmental adaptation on aerobic capacity at high altitude. Among subjects acclimatized during the developmental period, age at migration and length of residency are significantly correlated with aerobic capacity, while this is not the case when the subjects are acclimatized as adults. Adapted from Frisancho et al. (1973).

The extent to which developmental factors influence the attainment of aerobic capacity at high altitudes is illustrated in Fig. 1. These data show that, among lowland natives acclimatized to high altitudes during growth and development, the attainment of aerobic capacity is directly related to age at migration and length of residency. In contrast, when subjects were acclimatized to high altitudes as adults, age at migration and length of residency did not influence the attainment of aerobic capacity. In other words, it appears from the investigations that the attainment of normal aerobic capacity at high altitudes is influenced by adaptations during the developmental period (Frisancho et al., 1973).

BODY SIZE AND AEROBIC CAPACITY. - As previously indicated it is generally 


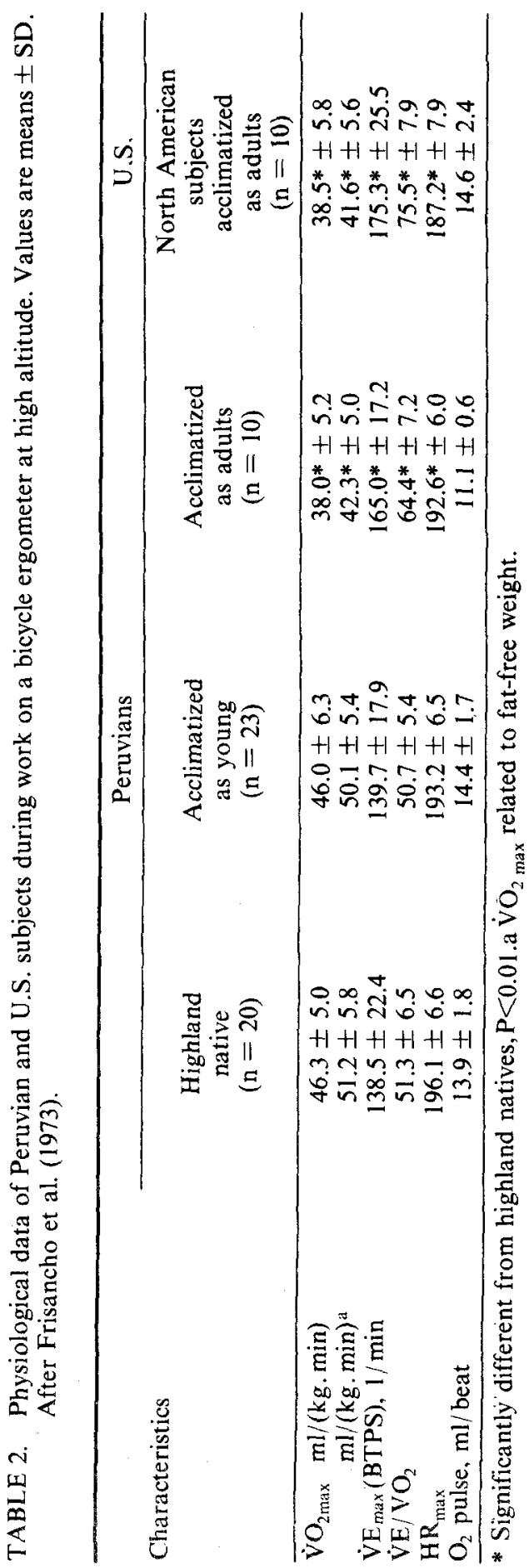


agreed that growth in body size at high altitudes is retarded when compared to that at sea level. As a result of this delayed growth, highland adult natives are shorter and lighter in weight than their sea level counterparts. It must be noted, however, that this delayed growth among highland children is not associated with any pathological symptoms, and that these adults have a work capacity comparable to that of sea level inhabitants. Therefore, the delayed growth found among high altitude children probably reflects part of the adaptive mechanisms that enable them to adapt to the highland environment. In other words, small body size both during development and adulthood may represent a byproduct of adaptive responses to the high altitude environment. In order to test this hypothesis we have studied the maximal aerobic capacity of young adult Quechua subjects selected for extremes of stature (Frisancho, Velasquez and Sanchez, 1975). The sample consisted of two subgroups of high-altitude young adult Quechua natives: 22 subjects characterized by small body size and 18 subjects characterized by large body size. The stature of the small body size group ranged from 150 to $159 \mathrm{~cm}$, and the stature of the large body size group ranged from 162 to $174 \mathrm{~cm}$. The

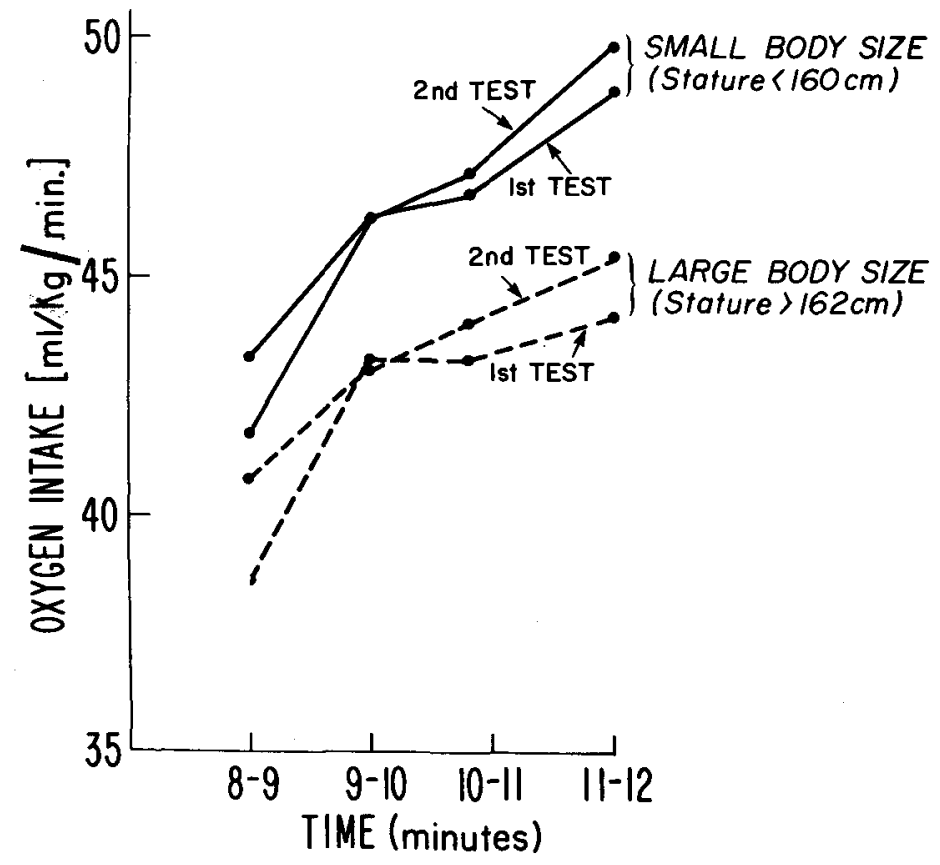

Fig. 2. High altitude Quechua natives tested at $3,840 \mathrm{~m}$. Increased aerobic capacity is associated with small body size. Adapted from Frisancho, Velasquez and Sanchez (1975).

age in both groups ranged from eighteen to twenty-five years. These subjects were serving as soldiers at the Army Headquarters of the city of Puno (3,840 m). They were under the same training program and their length of service in the army ranged from 0.9 to 1.9 years. Their nutritional and health status was good, as judged by both the anthropometric measurements and the reports of the medical officers. They all were of blood type $\mathrm{O}$ and $\mathrm{Rh}+$.

As shown in Fig. 2, during each minute of maximal work and in both tests the short subjects attained a significantly $(\mathbf{P}<0.005 ; \mathbf{P}<0.01)$ greater oxygen intake $(\mathrm{ml} /(\mathrm{kg} / \mathrm{min})$ 
than their tall counterparts. However, the ventilation rate and maximal work loads of the short subjects were comparable to those attained by the tall natives.

These findings suggest that small subjects at high altitude have an enhanced functional adaptation. Hence, it would appear that delayed growth leading to small body size among highland populations is part of the adaptive mechanism which enables these populations to adapt to the highland environment. However, the mechanisms whereby small individuals are able to maintain a higher aerobic capacity await clarification through experimental studies.

\section{CONCLUSIONS}

The present review has been concerned with evaluating the developmental adaptive responses that enable the organism to survive under hypoxic conditions. Recent publications by Petropoulos and Timiras (1974) and Mazess (1975) should be consulted for an updated review of the literature.

The available evidence suggests that developmental responses are of major importance in enabling man to attain a full functional adaptation to high altitude hypoxia. Thus, it is postulated that the differences between highland and lowland natives in physiological performance and morphology are mostly due to adaptations acquired during the developmental period. This postulate is supported by a recent investigation of Lahiri et al. (1976), which studied the control of ventilation by sea level and high altitude newborns, children and adults. The study demonstrated that the blunted ventilatory response to hypoxia and large lung volumes developed gradually after birth; the offspring of lowlanders born and raised at high altitude also showed the same ventilatory responses as the native highlanders.

The hypothesis that developmental adaptations account for most of the differences in physiological performance and morphology between highland and lowland natives is based upon the theoretical assumption that the respective contributions of genetic and environmental factors vary with the developmental stage of the organism, and in general the earlier the stage the greater the influence of the environment. It must be noted, however, that the principle of developmental sensitivity and plasticity does not necessarily imply greater adaptive responses in all biological parameters. This will depend on the developmental stage of the organism, the type of organism, and the particular functional process that is affected. Thus, an adaptive response in a physiological parameter does not necessarily imply an adaptive response in a morphological trait, although such a trait may depend on a successful functional adaptation. Weinstein and Haas (1975) studied women living in Leadville, Colorado (3,000 m) and found that those acclimatized to high altitude prior to adolescence had offspring with lower birth weights than those acclimatized after adolescence or during adulthood. These differences in birth weight, rather than being contradictory to the developmental hypothesis, are in my opinion probably related to the fact that, as previously indicated, hypoxia leads to growth delay and smaller adult body size, which in turn, may affect the physiological and morphological development necessary for adequate prenatal growth. In other words, what we consider a deficiency in a given variable may actually reflect the indirect influence of the adaptive success of another variable. Successful adaptation to high altitude hypoxic stress is a complex phenomenon which develops through a synchronized interdependence of various physiological and morphological reactants interrelated within the lifespan of the organism. Homeostatic interdependence does not imply uniform correlations for all physiological and morphological variables. Continuous exposure to hypoxic stress results in an integrated systemic potentiation of all homeostatic processes of the organism.

Future research, then, must be addressed to determining the specific critical period at which a given parameter is most affected and the specific period at which the most adaptive responses occur. In view of our drastically changing ecosystem, such informa- 
tion will improve not only our understanding of man's mechanisms of adaptation to high altitude hypoxia, but also will further our comprehension of man's capacity for adaptation to various adverse environments.

\section{ACKNOWLEDGEMENTS}

Supported in part by grant HL-13805 from the National Institutes of Health. Various phases of the present investigation were conducted in cooperation with the Institute of Andean Biology of the National University of San Marcos of Peru and the International Biological Programme of the United States. The assistance of Ms. Jane E. Klayman and Ms. Donna Monroe in the preparation of this manuscript is appreciated.

\section{REFERENCES}

ADAMS, W. C., BERNAUER, E. M., DILL, D. B. and BOMAR, J. B. (1975). Effects of equivalent sea-level and altitude training on $\mathrm{VO}_{2} \max$ and running performance. J. appl. Physiol. 39: 262-266.

ARIAS-STELLA, J. and RECAVARREN, S. (1962). Right ventricular hypertrophy in native children living at high altitude. Amer. J. Pathol., 41: 55-59.

ARIAS-STELLA, J. and SALDANA, M. (1962). The muscular pulmonary arteries in people native to high altitude. Med. Thorac., 19: 484-492.

BAKER, P. T. (1969): Human adaptation to high altitude. Science, 163: 1149-1156.

BALKE, B. (1960): Work capacity at altitude. In: Science and Medicine of Exercise and Sports, W. R. Johnson (ed.), Harper and Brothers, New York, 339-347.

BANCHERO, N., SIME, F., PENALOZA, D., CRUZ, J., GAMBOA, R. and MARTICORENA, E. (1966): Pulmonary pressure, cardiac output and arterial oxygen saturation during exercise at high altitude and at sea level. Circulation, 33: 249-262.

BARTLETT, D. and REMMERS, J. E. (1971): Effects of high altitude exposure on the lungs of young rats. Resp. Physiol., 13: 116-125.

BARTLETT, D. Jr. (1972): Postnatal development of the mammalian lung. In: Regulation of Organ and Tissue Growth, R. Goss (ed.), Academic Press, New York, 197-209.

BOYCE, A. J., HAIGHT, J. S. J., RIMMER, D. B. and HARRISON, G. A. (1974): Respiratory Function in Peruvian Quechan Indians. Ann. Hum. Biol., I: 137-148.

BURRI, P. H. and WEIBEL, E. R. (1971): Morphometric estimation of pulmonary diffusion capacity. Il. Effect of $\mathrm{PO}_{2}$ on the growing lung. Adaptation of the growing rat lung to hypoxia and hyperhypoxia. Resp. Physiol., 11: 247-264.

BUSKIRK, E. R., KOLliAS, J., AKERS, R. F., PROKOP, E. K. and PICONREATEGUI, E. (1967): Maximal performance at altitude and on return from altitude in conditioned runners. J. appl. Physiol., 23: 259-266.

CONSOLAZIO, C. F., JOHNSON, H. G., MATAUSH, L. O., NELSON, R. A. and ISAAC, G. J. (1967): Respiratory function in normal young adults at 3475 and 4300 meters. U.S. Army Med. Res. and Nutrition Lab., Report No. 300.

CUNNINGHAM, E. L., BRODY, J. S. and JAIN, B. P. (1974): Lung growth induced by hypoxia. J. appl. Physiol., 37: 362-366.

DEGRAFF, A. C., GROVER, R. F., JOHNSON, R. L., HAMMOND, J. W. and MILLER, J. M. (1970): Diffusing capacity of the lung in Caucasians native to 3,100 m. J. appl. Physiol., 29: 71-76.

DELAQUERRIERE-RICHARDSON, L., FORBES, E. S. and VALDIVIA, E. (1965): Effect of simulated high altitude on the growth rate of albino guinea pigs. J. appl. Physiol., 20: 1022-1025. 
DILL, D. B., MYHRE, L. G., BROWN, D. K., BURRUS, K. and GEHLSEN, G. (1967): Work capacity in chronic exposures to altitude. J. appl. Physiol., 23: 555-560.

DUNNILL, M. S. (1962): Postnatal growth of the lung. Thorax, 17: 329-333.

ELSNER, R. W., BOLSTAD, A. and FORNO, C. (1964): Maximum oxygen consumption of Peruvian Indians native to high altitude. In: The Physiological Effects of High Altitude, W. H. Weihe (ed.), Pergamon Press, Oxford, 217-221.

FAULKNER, J., KOLLIAS, J., FAVOUR, O., BUSKIRK, E. and BALKE, B. (1968): Maximum aerobic capacity and running performance at altitude. J. appl. Physiol., 24: 685-691.

FRISANCHO, A. R. (1969): Human growth and pulmonary function of a high altitude Peruvian Quechua population. Hum. Biol., 41: 365-379.

FRISANCHO, A. R. (1970): Developmental responses to high altitude hypoxia. Amer. J. phys. Anthrop., 32: 401-408.

FRISANCHO, A. R. (1975): Functional adaptation to high altitude hypoxia. Science, 187: 313-319.

FRISANCHO, A. R. (1976): Growth and morphology at high altitude. Part II: Adult morphology. In: Man in the Andes, P. T. Baker and M. A. Little (ed.), Dowden, Hutchinson and Sons, Inc., Stroudsburg, Pennsylvania, 200-207.

FRISANCHO, A. R. and BAKER, P. T. (1970): Altitude and growth: a study of the patterns of physical growth of a high altitude Peruvian Quechua population. Amer. J. phys. Anthrop., 32: 279-292.

FRISANCHO, A. R., VELASQUEZ, T. and SANCHEZ, J. (1973): Influences of developmental adaptation on lung function at high altitude. Hum. Biol., 45: 583-594.

FRISANCHO, A. R., VELASQUEZ, T. and SANCHEZ, J. (1975): Possible adaptive significance of small body size in the attainment of aerobic capacity among high altitude Quechua natives. In: Biosocial Interrelations in Population Adaptation, E. Watts, F. E. Johnston and G. Lasker (ed.), Mouton Publishers, 55-64.

FRISANCHO, A. R., MARTINEZ, C., VELASQUEZ, T., SANCHEZ, J. and MONTOYE, H. (1973): Influence of developmental adaptation on aerobic capacity at high altitude. J. appl. Physiol., 34: 176-180.

GRAHN, D. and KRATHCMAN, J. (1963): Variation in neonatal death rate and birth weight in the United States and possible relations to environmental radiation, geology and altitude. Amer. J. Hum. Genet., 15: 329-352.

GROVER, R. F., REEVES, J. T., WILL, D. H. and BLOUNT, S. G. (1963): Pulmonary vasoconstruction in steers at high altitude. J. appl. Physiol., 18: 567-570.

GROVER, R. F., REEVES, J. T., GROVER, E. B. and LEATHERS, J, E. (1967): Muscular exercise in young men native to $3,100 \mathrm{~m}$ altitude. $\mathrm{J}$. appl. Physiol., 22: 555-564.

GUlERIA, J. S., PAUDE, J. N., SETHI, P. K. and RAY, S. B. (1971): Pulmonary 'diffusing capacity at high altitude. J. appl. Physiol., 31: 536-543.

HAAS, J. D. (1973): Altitudinal Variation and Infant Growth and Development in Peru. Ph.D. Thesis, Pennsylvania State University, University Park.

HARRIS, C. and HANSEN, J. E. (1966): Electrocardiographic changes during exposure to high altitude. Amer. J. Cardiol., 18: 183-190.

HOFF, C. (1974): Altitudinal variations in the physical growth and development of Peruvian Quechua. Homo., 24: 87-99.

HURTADO, A. (1932). Respiratory adaptation in the Indian natives of the Peruvian Andes. Studies at high altitude. J. phys. Anthrop., 17: 137.

HURTADO, A. (1964): Animals in high altitudes: resident man. In: Adaptation to the Environment. D. B. Dill, E. F. Adolph and C. G. Wilber (ed.), Handbook of Physiology, Section 4, Wash. D.C., Amer. Physiol. Soc., 843-860. 
JOHNSON, R. L., TAYLOR, H. F., DEGRAFF, A. C. (1965): Functional significance of a low pulmonary diffusing capacity for carbon monoxide. J. clin. Invest., 44: 789-800.

KELLEY, F. C. and PACE, N. (1968): Etiological considerations in neonatal mortality among rats at moderate high altitude $(3,800 \mathrm{~m})$. Amer. J. Physiol., 214: 1168 1175 .

KOLLIAS, J., BUSKIRK, E. R., AKERS, R. F., PROKOP, E. K., BAKER, P. T. and PICON-REATEGUI, E. (1968). Work capacity of long-time residents and newcomers to altitude. J. appl. Physiol., 24: 792-799.

KRUGER, H. and ARIAS-STELLA, J. (1970): The placenta and the newborn infant at high altitudes. Amer. J. Obstet. Gynec., 106: 586-591.

LAHIRI, P. (1966): Muscular exercise in the Himalayan high-altitude residents. Fed. Proc., 25: 1392-1396.

LAHIRI, S., DELANEY, R. G., BRODY, J. S., SIMPSER, M., VELASQUEZ, T., MOTOYAMA, E. K. and POLGAR, C. (1976): Relative role of environmental and genetic factors in respiratory adaptation to high altitude. Nature (Lond.), 261: 133-135.

LICHTY, J. A., TING, R. Y., BRUMS, P. D. and DYAR, E. (1957): Studies of babies born at high altitudes. I. Relation of altitude to birth weight. II. Measurement of birth weight, body length and head size. III. Arterial oxygen saturation and hematocrit values at birth. Amer. J. Dis. Child., 93: 666-677.

MARTICORENA, E., PENALOZA, D., SEVERINO, J. and HELLRIEGEL, K. (1962): Insidencia de la persistencia del conduto arterioso en las grandes alturas. Memorias del IV Congreso Mundial de Cardiologia, Mexico, I-A: 155-159.

MAZESS, R. B. (1969): Exercise Performance of Indian and White high altitude residents. Hum. Biol., 41: 494-518.

MAZESS, R. B. (1975): Human Adaptation to High Altitude. In: Physiological Anthropology. A. Damon (ed.), Oxford University Press, London,

MCCLUNG, J. P. (1967): Placental and birth weights in two Peruvian populationsaltitude effect. Amer. J. phys. Anthrop., 27: 248.

MCCLUNG, J. P. (1969): Effects of high altitude on human birth; observations on mothers, placentas and the newborn in two Peruvian populations. Harvard University.Press, Cambridge, Mass.

NELSON, M. L. and SREBNIK, H. H. (1970): Comparison of the reproductive performance of rats at high altitude $(3,800 \mathrm{~m})$ and at sea level. Int. J. Biometeor., 14: 187-193.

PAWSON, I. G. (1974): The growth and development of high altitude children with special emphasis on populations of Tibetan origin in Nepal. Ph.D. thesis. Pennsylvania State University, University Park.

PENALOZA, D., SIME, F., BANCHERO, N., GAMBOA, R., CRUZ, J. and MARTICORENA, E. (1963): Pulmonary hypertension in healthy men born and living at high altitudes. Amer. J. Cardiol., 11: 150.

PENALOZA, D., ARIAS-STELLA, J., SIME, F., RECAVARREN, S. and MARTICORENA, E. (1964): The heart and pulmonary circulation in children at high altitudes. Pediatrics, 34: 568-582.

PETROPOULOS, E. A. (1971): Rat placental growth and metabolism at high altitude $(3,800 \mathrm{~m})$. Anat. Rec., 169: 401-402.

PETROPOULOS, E. A. and TIMIRAS, P. S. (1974): Biological Effects of High Altitude as related to increased solar radiation, temperature fluctuations and reduced partial pressure of oxygen. In: Progress in Biometeorology, Division A, vol. 1. The Effect of Weather and Climate on Man and his Living Environment, Swets \& Zeitlinger, Amsterdam, 295-328.

RAHN, H. and HAMMOND, D. (1952): The vital capacity at reduced barometric pressure. J. appl. Physiol., 4: 715-719. 
REMMERS, J. E. and MITHOEFER, J. C. (1969): The carbon monoxide diffusing capacity in permanent residents at high altitudes. Resp. Physiol., 6: 233-244.

ROTTA, A., CANEPA, A., HURTADO, A., VELASQUEZ, T. and CHAVEZ, R. (1956): Pulmonary circulation at sea level and at high altitudes. J. appl. Physiol., 9: 328-332.

SANCHEZ, R. A. (1963): Estudio microscopio de 100 placentas en el Hospital Esperanza de Cerro de Pasco. Tesis de Bachillerato Universidad Nacional Mayor de San Marcos, Facultad de Medicina, Lima, Peru.

SIME, F., BANCHERO, N., PENALOZA, D., GAMBOA, R., CRUZ, J. and MARTICORENA, E. (1963): Pulmonary hypertension in children born and living at high altitude. Amer. J. Cardiol., 11: 143-149.

SOBREVILLA, L. A., ROMERO, J., MONCLOA, F., DONAYRE, J. and GUERRA-GARCIA, R. (1967): Endocrine studies at high altitude. III. Urinary gonadotropins in subjects native to and living at 14,000 feet and during acute exposure of men living at sea level to high altitudes. Acta. endocr. (Kbh.), 56: 369-375.

SOBREVILlA, L. A. and SALAZAR, F. (1968): High altitude hyperuricemia. Proc. Soc. exp. Biol. (N.Y.), 129: 890-895.

SOBREVILLA, L. A. (1971): Analisis Matematico de la Relacion Ponderal Placenta: Recien Nacido en la Altura. In: Estudios sobre la Gestacion y el Recien Nacido en la Altura, R. Guerra-Garcia (ed.), Instituto de Investigaciones de la Altura, Universidad Peruana Cayetano Heredia, Peru, vol. 17.

U. S. Dept. of Health, Education and Welfare (1965): Weight at Birth and Survival of the Newborn. Publ. Hlth. Service Publ. 1000, series 23, 3, Washington, D.C.

VELASQUEZ, T. M. (1964): Response to physical activity during adaptation to altitude. In: The Physiological Effects of High Altitude, W. H. Weihe (ed.), Pergamon Press, Oxford, 289-299.

VELASQUEZ, T. and FLORENTINI, E. (1966): Maxima capacidad de difucion del pulmon en nativos de la altura. Archivos Instituto Biologia Andina, 1: 179-187.

WEIHE, W. H. (1965): Influence of altitude and cold on pregnancy and lactation of ráts fed on two different diets. Int. J. Biometeor., 9: 43-52.

WEINSTEIN, R. S. and HAAS, J. D. (1975): Maternal adaptation and infant birth weight and mortality at high altitude. Abstract. Amer. J. phys. Anthrop., 42: 337. 